\title{
Water defluoridation by carbonate calcined and uncalcined Layered Double Hydroxides (LDHs)
}

\author{
Elisabetta Dore $^{1}$, and Franco Frau ${ }^{1, *}$ \\ ${ }^{1}$ Department of Chemical and Geological Sciences, University of Cagliari, 09127 Cagliari, Italy
}

\begin{abstract}
Carbonate Layered Double Hydroxides (LDHs) with different cationic composition and $\mathrm{M}^{2+} / \mathrm{M}^{3+}$ molar ratio were tested, both untreated and calcined, for water defluoridation. The defluoridation capacity of calcined LDHs, produced by intercalation during the reconstruction of lamellar structure, is more effective than the anion exchange of untreated LDHs. Among the calcined LDHs tested, that with $3 \mathrm{Mg} /(0.5 \mathrm{Al}+0.5 \mathrm{Fe})$ molar ratio yields a maximum fluoride sorption capacity up to $92.3 \mathrm{mg} / \mathrm{g}$, in spite of the high $\mathrm{pH}$ value (up to 12) of the experiments. After four cycles of regeneration by calcination and subsequent water defluoridation, this LDH composition maintains more than $80 \%$ of its fluoride removal capacity.
\end{abstract}

\section{Introduction}

Fluorine, in the fluoride form $\left(\mathrm{F}^{-}\right)$, is recognized as an important micronutrient for human health but the excess of fluoride intake can cause serious health problems, such as dental and skeletal fluorosis, neurological disorder and Alzheimer syndrome [1]. The World Health Organization [2] has recommended the limit of $\mathrm{F}^{-}$concentration for drinking water at $1.5 \mathrm{mg} / \mathrm{L}$; however the consumption of water with high $\mathrm{F}^{-}$concentration is a global issue and affects millions of people in the rural areas of the East African Rift Valley (EARV) [3, 4]. The FLOWERED project is a European Union Horizon2020 project that aims to develop a defluoridation method for drinking water suitable for the rural communities of the EARV. Its objective is a low-cost method, easy-to-use and able to remove efficiently $\mathrm{F}^{-}$ without altering the water quality.

The work presented here is contained within the framework of the FLOWERED project and aims to develop a method of water defluoridation using Layered Double Hydroxides (LDHs), a group of minerals with a high potential for the reduction of hazardous concentrations of anions from solution [5-8]. LDHs have a wide compositional variability, with the following general stoichiometry $\mathrm{M}^{2+}{ }_{1-\mathrm{x}} \mathrm{M}^{3+}{ }_{\mathrm{x}}(\mathrm{OH})_{2}\left(\mathrm{~A}^{\mathrm{n}-}\right)_{\mathrm{x} / \mathrm{n}} \cdot \mathrm{mH}_{2} \mathrm{O}$, where $\mathrm{M}^{2+}$ and $\mathrm{M}^{3+}$ are respectively divalent and trivalent metals in the octahedral brucite-like sheets, and $\mathrm{A}^{\mathrm{n}-}$ are anions in the interlayer region. LDHs can remove anions from solution through anion exchange in the interlayer region (untreated LDHs) and adsorption on external surface, as well as by incorporation during rehydration and reconstruction of the lamellar structure (calcined LDHs) [9]. Previous research has identified the potential use of LDHs

*Corresponding author: frauf@unica.it 
for water defluoridation $[3,6,7]$; however, due to different synthesis methods and experimental conditions adopted, often the results are not comparable. Moreover, the $\mathrm{F}^{-}$ sorption capacity of LDHs reported by several authors is frequently determined under highly specific conditions, such as a narrow range of solution $\mathrm{pH}$ that cannot be adopted in the context of the FLOWERED project $[6,7]$.

This work examined the $\mathrm{F}^{-}$removal capacity of carbonate LDHs, both calcined and untreated, with different cationic composition and $\mathrm{M}^{2+} / \mathrm{M}^{3+}$ molar ratio. Carbonate LDHs have been chosen because they can be synthesized with a simple coprecipitation method and do not release undesirable anions (e.g. $\mathrm{NO}_{3}^{-}, \mathrm{SO}_{4}{ }^{2-}$ ) to solution during $\mathrm{F}^{-}$removal. In accordance with the aims of the FLOWERED project, the $\mathrm{F}^{-}$sorption experiments have been performed as simply as possible, and without controlling the solution $\mathrm{pH}$. Moreover, the $\mathrm{F}^{-}$removal capacity of regenerated $\mathrm{LDH}$ was investigated because it would reduce significantly the amount of waste materials after water defluoridation.

\section{Materials and methods}

Synthetic carbonate LDHs of different cationic composition $\left(\mathrm{Mg}^{2+}, \mathrm{Zn}^{2+}, \mathrm{Al}^{3+}, \mathrm{Fe}^{3+}\right)$ and $\mathrm{M}^{2+} / \mathrm{M}^{3+}$ molar ratio (2, 3 and 4$)$ were prepared with a simple coprecipitation method at constant $\mathrm{pH}$, room atmosphere and temperature [5]. A solution with the desired metals in an established molar ratio of $0.25 \mathrm{M}$, obtained by dissolving the salts in distilled water, was dropped into a reactor containing a $0.2 \mathrm{M} \mathrm{Na}_{2} \mathrm{CO}_{3}$ solution, and the precipitation was induced at constant $\mathrm{pH}$ by adding dropwise $1 \mathrm{M} \mathrm{NaOH}$. After 48 hours of aging at $65{ }^{\circ} \mathrm{C}$, the LDHs were washed with distilled water and recovered through filtration, then dried at room temperature. Calcination was performed at $450{ }^{\circ} \mathrm{C}$ for 4 hours. A standard $\mathrm{F}^{-}$stock solution $(5000 \mathrm{mg} / \mathrm{L})$, prepared dissolving $\mathrm{NaF}$ in Milli- $\mathrm{Q}^{\circledR}$ water, was used, by appropriate dilution, to prepare all solutions for sorption experiments.

A first series of sorption experiments was performed to select the LDHs with the most effective composition: $0.2 \mathrm{~g}$ of LDHs, both untreated and calcined, were suspended in 50 $\mathrm{ml}$ of $100 \mathrm{mg} / \mathrm{L} \mathrm{F}^{-}$solution for 18 hours, under agitation through a rotor system $(40 \mathrm{rpm})$. Successively, a selected LDH with the highest removal efficiency was used to investigate the effect of starting $\mathrm{F}^{-}$concentration and sorbent dosage on $\mathrm{F}^{-}$removal capacity, together with the possibility of reusing the $\mathrm{LDH}$ after regeneration by calcination. For this last purpose, four cycles of calcination $/ \mathrm{F}^{-}$sorption experiment/calcination were repeated: the sorption experiments were performed by suspending $0.2 \mathrm{~g}$ of LDH in $50 \mathrm{ml}$ of solution with a starting $\mathrm{F}^{-}$concentration of $50 \mathrm{mg} / \mathrm{L}$, for 24 hours under agitation through a rotor system (40 rpm). At the end of the reaction time, the fraction of $\mathrm{LDH}>12 \mu \mathrm{m}$ was recovered and washed with distilled water, dried at room temperature, calcined again at $450{ }^{\circ} \mathrm{C}$ for 4 hours and, finally, reused to repeat the sorption experiment.

The $\mathrm{pH}$ of solutions was monitored during all experiments, but not modified. The $\mathrm{F}^{-}$ concentration in solution before and at the end of the experiments was determined by a potentiometer with an ion selective fluoride electrode, adding TISAB III solution in the recommended volume to buffer $\mathrm{pH}$ and avoid the possible interference of metallic complexes. The concentration of dissolved metals $(\mathrm{Mg}, \mathrm{Zn}, \mathrm{Fe}$ and $\mathrm{Al})$ at the end of the experiments was analyzed by inductively coupled plasma optical emission spectroscopy (ICP-OES, ARL Fisons 3520).

The mineralogical characterization of LDHs, before and after the experiments, was performed by measuring XRD patterns in the $3-80{ }^{\circ} 2 \theta$ angular range on an automated PANalytical X'pert Pro diffractometer, with Ni-filtered $\mathrm{Cu} \mathrm{K} \mathrm{K}_{\alpha 1}$ radiation $(\lambda=1.54060 \AA)$, operating at $40 \mathrm{kV}$ and $40 \mathrm{~mA}$, using the $\mathrm{X}^{\prime}$ Celerator detector. 


\section{Results and discussion}

LDHs are marked with the symbols of metals in the brucite-like sheets, the number at the front indicates the $\mathrm{M}^{2+} / \mathrm{M}^{3+}$ molar ratio and the suffixes $-\mathrm{C}$ and -calc indicate the untreated and the calcined LDHs, respectively. As an example, $3 \mathrm{MgAlFe}-\mathrm{C}$ indicates an uncalcined carbonate $\mathrm{LDH}$ with the following cationic composition $3 \mathrm{Mg}^{2+} /\left(0.5 \mathrm{Al}^{3+}+0.5 \mathrm{Fe}^{3+}\right)$.

In agreement with previous studies, calcined LDHs are more effective at defluorination than untreated ones; moreover, compositions with $\mathrm{Mg}$ remove $\mathrm{F}^{-}$better than the composition with $\mathrm{Zn}$ (Fig. 1A), perhaps due to the higher atomic weight of $\mathrm{Zn}$ compared to $\mathrm{Mg}$ [7]. The $3 \mathrm{MgAlFe}-\mathrm{cal}$ and $4 \mathrm{MgAlFe}$-cal LDHs remove the largest amounts of $\mathrm{F}^{-}$, probably as a consequence of the higher specific surface area due to the contemporary presence of $\mathrm{Al}$ and $\mathrm{Fe}$ in the brucite-like sheets [8].

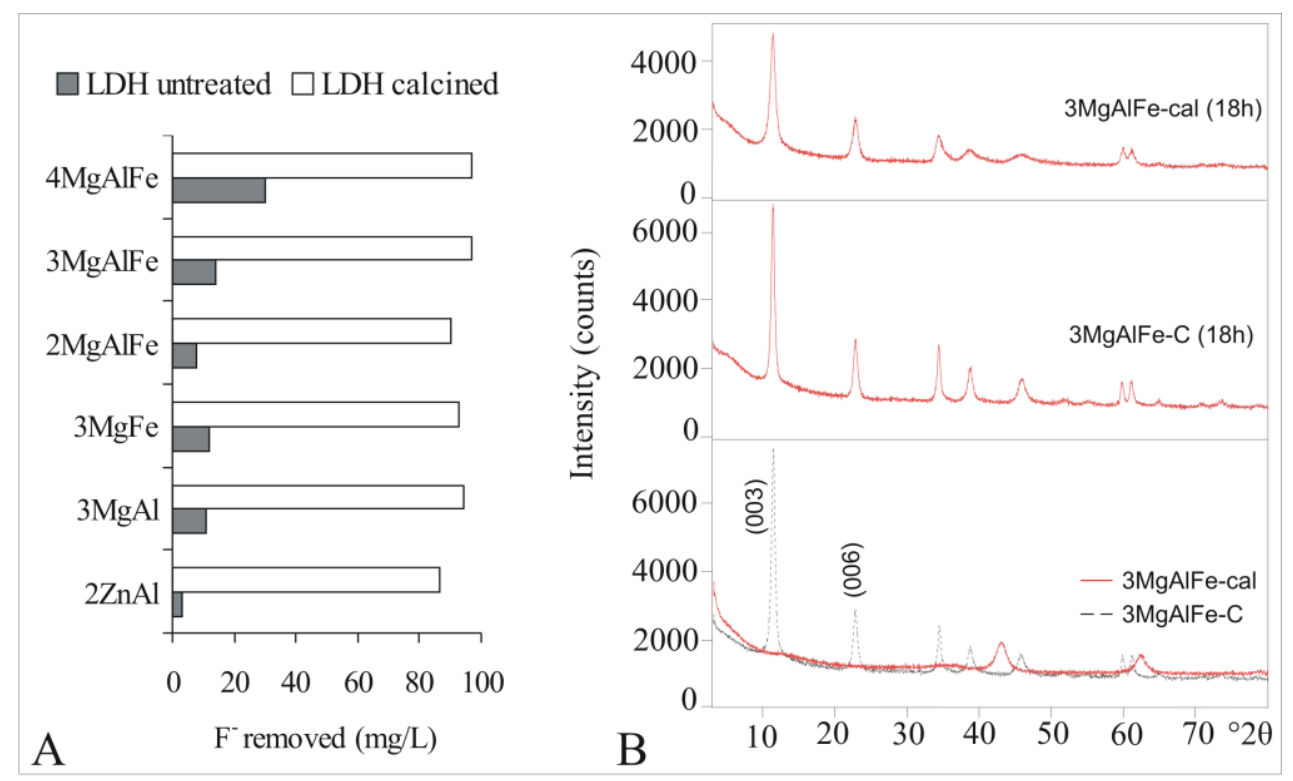

Fig. 1. (A) Concentration of $\mathrm{F}^{-}$removed from solution by untreated and calcined synthetic LDHs at the end of sorption experiments; (B) XRD patterns of $3 \mathrm{MgAlFe}-\mathrm{C}$ and its calcined product $3 \mathrm{MgAlFe}-$ cal before and after the sorption experiments.

Figure 1B illustrates the XRD patterns for the selected sorbent $3 \mathrm{MgAlFe}-\mathrm{C}$ and its calcined product $3 \mathrm{MgAlFe}$-cal, before and after the experiments. The XRD pattern of $3 \mathrm{MgAlFe}-\mathrm{C}$ shows the typical (003) and (006) basal reflections of the LDH structure; the basal reflections are no longer detectable after calcination (3MgAlFe-cal) due to the collapse of the lamellar structure, whereas two broad peaks at the angular positions 43.3 and $62.6^{\circ} 2 \theta$ can be ascribed to a low ordered $\mathrm{MgO}$ with $\mathrm{Al}$ and $\mathrm{Fe}$ dispersed in the structure [8]. The $3 \mathrm{MgAlFe}-\mathrm{C}(18 \mathrm{~h}) \mathrm{XRD}$ pattern after the sorption experiment does not show significant changes with respect to the original phase. The $3 \mathrm{MgAlFe}-\mathrm{cal}(18 \mathrm{~h}) \mathrm{XRD}$ pattern shows the reconstruction of the lamellar structure, and the absence of residual peaks of low ordered $\mathrm{MgO}$ suggests a complete reaction of rehydration, with uptake of $\mathrm{F}$ - from solution and its entry in the interlayer region.

The solution $\mathrm{pH}$ dramatically increased at the end of the experiments performed with calcined LDHs (Table 1), as a consequence of the reconstruction of the layered structure [8]. Low amounts of $\mathrm{Mg}$ determined in solution at the end of the experiments indicate a slight dissolution of LDHs $(<1 \%)$; the dissolved amounts of $\mathrm{Al}$ and $\mathrm{Fe}$ are very low or 
below the detection limit, with the only exception of the experiment performed with 2ZnAlcal. The $3 \mathrm{MgAlFe}$-cal phase was selected to carry out further experiments on the basis of these results.

Table 1. The $\mathrm{Mg}, \mathrm{Zn}, \mathrm{Al}$ and $\mathrm{Fe}$ concentrations and $\mathrm{pH}$ values determined in solution at the end of $\mathrm{F}^{-}$ sorption experiments.

\begin{tabular}{|l|c|c|c|c|c|c|c|c|c|}
\hline $\begin{array}{c}\text { untreated } \\
\text { LDH }\end{array}$ & $\mathbf{p H}$ & $\mathbf{M g}$ or Zn & $\mathbf{A l}$ & $\mathbf{F e}$ & $\begin{array}{c}\text { calcined } \\
\text { LDH }\end{array}$ & $\mathbf{p H}$ & $\mathbf{M g}$ or Zn & $\mathbf{A l}$ & $\mathbf{F e}$ \\
\hline & & $\mathrm{mg} / \mathrm{L}$ & $\mathrm{mg} / \mathrm{L}$ & $\mathrm{mg} / \mathrm{L}$ & & & $\mathrm{mg} / \mathrm{L}$ & $\mathrm{mg} / \mathrm{L}$ & $\mathrm{mg} / \mathrm{L}$ \\
\hline $2 \mathrm{ZnAl}$ & 7.8 & $<0.04$ & $<0.24$ & & $2 \mathrm{ZnAl}$ & 11.8 & $<0.04$ & 10.8 & \\
\hline $3 \mathrm{MgAl}$ & 9.3 & 3.53 & $<0.1$ & & $3 \mathrm{MgAl}$ & 11.8 & 0.71 & 0.65 & \\
\hline $3 \mathrm{MgFe}$ & 9.6 & 5.18 & & $<0.02$ & $3 \mathrm{MgFe}$ & 11.9 & 0.11 & & $<0.02$ \\
\hline $3 \mathrm{MgAlFe}$ & 9.3 & 6.33 & $<0.1$ & $<0.02$ & $3 \mathrm{MgAlFe}$ & 11.8 & $<0.05$ & $<0.1$ & $<0.02$ \\
\hline $2 \mathrm{MgAlFe}$ & 9.3 & 5.50 & $<0.1$ & $<0.02$ & $2 \mathrm{MgAlFe}$ & 11.8 & 0.26 & 1.48 & 0.18 \\
\hline $4 \mathrm{MgAlFe}$ & 9.8 & 6.43 & $<0.1$ & $<0.02$ & $4 \mathrm{MgAlFe}$ & 11.9 & 0.08 & $<0.1$ & $<0.02$ \\
\hline
\end{tabular}

The solution $\mathrm{pH}$ value, determined at the end of the experiments performed with different starting $\mathrm{F}^{-}$concentrations and different sorbent dosages, ranges between 11.5 and 12.4 (not shown). Even if the increase of $\mathrm{pH}$ affects the $\mathrm{F}^{-}$removal capacity of LDHs as a consequence of the increased competitive effect of $\mathrm{CO}_{3}{ }^{2-}$ and $\mathrm{OH}^{-}$anions in alkaline conditions, the $\mathrm{F}^{-}$sorption capacity determined is very promising.

Figure $2 \mathrm{~A}$ shows that the removal efficiency decreases by increasing the starting $\mathrm{F}^{-}$ concentration, but the amount of $\mathrm{F}^{-}$sorbed increases (from $12.3 \mathrm{mg} / \mathrm{g}$ to $92.3 \mathrm{mg} / \mathrm{g}$ ) until the starting $\mathrm{F}^{-}$concentration of $1000 \mathrm{mg} / \mathrm{L}$. The curve then reaches the plateau indicating that the saturation of the sorption sites occurs.

By increasing the sorbent dosage (Fig. 2B), the percentage of $\mathrm{F}^{-}$removed from solution increases from $43 \%$ to $97 \%$, as a consequence of the increase of the adsorptive sites. However, the $\mathrm{F}^{-}$sorption capacity decreases sharply from $85.9 \mathrm{mg} / \mathrm{g}$ to $24.2 \mathrm{mg} / \mathrm{g}$, because the sites occupied by $\mathrm{F}^{-}$decrease with respect to the sites available.
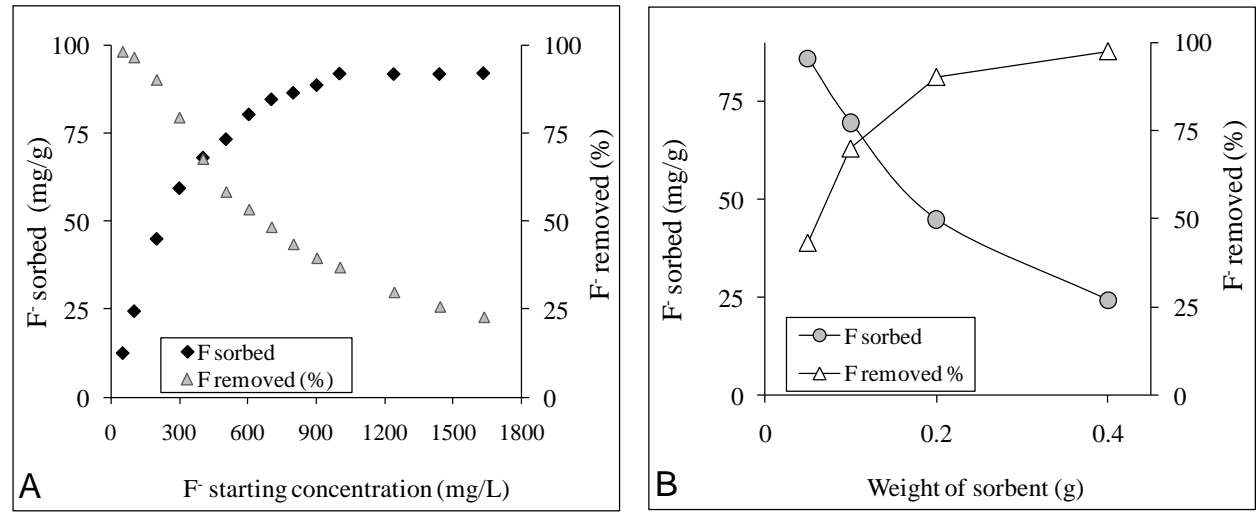

Fig. 2. (A) Effect of starting $\mathrm{F}^{-}$concentration on $3 \mathrm{MgAlFe}$-cal removal capacity (sorbent $=0.2 \mathrm{~g}$, solution $=50 \mathrm{ml}$, time $=24$ hours, agitation $=40 \mathrm{rpm}) ;(\mathbf{B})$ Effect of sorbent dosage on $3 \mathrm{MgAlFe}$-cal $\mathrm{F}^{-}$removal capacity (solution $=50 \mathrm{ml}, \mathrm{F}^{-}=200 \mathrm{mg} / \mathrm{L}$, time $=24$ hours, agitation $=40 \mathrm{rpm}$ ).

The results of regeneration tests show that $3 \mathrm{MgAlFe}$-cal can be successfully reused. In fact, more than $80 \%$ of the sorbent removal capacity is still preserved after four regeneration cycles (Fig. 3). 


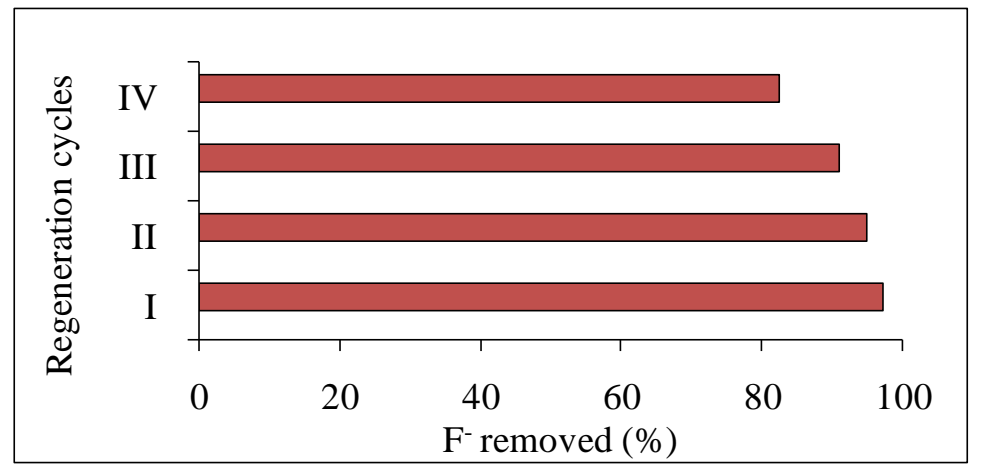

Fig. 3. The percentage of $\mathrm{F}^{-}$removed from solution by $3 \mathrm{MgAlFe}-\mathrm{cal}$ after regeneration cycles.

\section{Conclusions}

Carbonate LDHs with different composition and $\mathrm{M}^{2+} / \mathrm{M}^{3+}$ molar ratio have been tested, both calcined and untreated, for $\mathrm{F}^{-}$removal from solution. Results indicate that the best performing composition is the $3 \mathrm{MgAlFe}$-cal, which removes $\mathrm{F}^{-}$from solution by intercalation in the interlayer during the rehydration. Chemical analyses of solutions at the end of the experiments show a slight dissolution of sorbent, that does not affect the water quality, and a strong increase of solution $\mathrm{pH}$ (up to 12), that affects the $\mathrm{F}^{-}$removal capacity and decreases the quality of treated water. Nevertheless, $1 \mathrm{~g}$ of $3 \mathrm{MgAlFe}$-cal can remove up to $92.3 \mathrm{mg}$ of $\mathrm{F}^{-}$. Moreover, the sorbent can be regenerated and reused for at least four cycles of water defluoridation, maintaining more than $80 \%$ of the $\mathrm{F}^{-}$removal capacity. Therefore, results are promising and encourage further investigations, which should be mainly addressed to find a simple method to maintain the solution $\mathrm{pH}$ within the range of drinking water, thus making it possible to apply LDHs to reduce the effects on human health of excess fluoride in water.

This research was financially supported by Flowered project (Coordinator G. Ghiglieri), a Horizon 2020 European funded project (Grant Agreement - No. 690378) (www.floweredproject.org).

\section{References}

1. K.K. Yadav, N. Gupta, V. Kumar, S.A. Khan, A. Kumar, Environ. Int. 111, 80-108 (2018)

2. WHO Guidelines for Drinking-Water Quality, 4th ed. (2011)

3. M. Dessalegne, F. Zewge, N. Pfenninger, C.A Johnson, I. Diaz, Water Air Soil Poll., 227 (10), Art. $n^{\circ} 381$ (2016)

4. G. Ghiglieri, D. Pittalis, G. Cerri, G. Oggiano, HESS, 16 (2), 529-541 (2012)

5. E. Dore, F. Frau, Environ. Sci. Pollut. Res. 25 (1), 916-929 (2018)

6. D. Kang, X. Yu, S. Tong, M. Ge, J. Zuo, C. Cao, W. Song, Chem. Eng. J., 228, 731740 (2013)

7. L. Lv, J. He, M. Wei, D.G. Evans, X. Duan, J. Hazard. Mater., B113, 119-128 (2006)

8. D. Carriazo, M. del Arco, C. Martín, V. Rives, Appl. Clay Sci. 37 (3-4), 231-239

9. F. Cavani, F. Trifirò, A. Vaccari Catal. Today, 11(2), 173-301 (1991) 